\title{
LEADERSHIP DEVELOPMENT PRACTICES AND ORGANIZATIONAL OUTCOMES
}

\author{
MAHESH SUBRAMONY \\ Northern Illinois University \\ BH 245H, DeKalb, IL 60115 \\ JESSE SEGERS \\ University of Antwerp, Belgium \\ CLINT CHADWICK \\ University of Kansas, USA \\ Shyamsundar, A \\ Catalyst, India \\ John Dooney \\ SHRM, USA
}

\section{INTRODUCTION}

Recent theoretical developments suggest that leaders develop over time along two dimensions: intrapersonal which includes their leadership identity (Lord \& Hall, 2005) and skills (e.g., cognitive, meta-cognitive, and behavioral skills; e.g., Mumford, Campion, \& Morgeson, 2007); and interpersonal, i.e., the capacity to build relationships with others, enhancing social capital, and engaging in authentic leadership with followers (e.g., Avolio \& Gardner, 2005; Galli $\&$ Müller-Stewens, 2012). While this body of work provide insights into how and when leaders develop, and the effects of leaders' personal development on individual-level outcomes (see Day, Fleenor, Atwater, Sturm, \& McKee, 2014), there is very little theory to explain why firm-level leadership development practices are related to organizational performance outcomes. To this effect, we attempt to provide an explanation utilizing some key elements of resource-based theory (RBT; Barney, 1991; Barney, Ketchen, \& Wright, 2011). Utilizing a strategic resourcebased approach (e.g., Barney, et al., 2011; Shaw, Duffy, Johnson, \& Lockhart, 2005), we propose that firm-specific human- and social capital are strategic resources that are accumulated and developed through the actions of leaders, and that organizational investments in developing leaders through LDP's can help enhance this process by increasing leader's intrapersonal and interpersonal competencies, which will ultimately lead to an increase in organizational performance.

While extant studies have demonstrated the efficacy of individual leadership practices, (Douglas \& McCauley, 1999), it is common for multiple leadership development practices (e.g., training, coaching, and mentoring) to be implemented simultaneously. Also, drawing upon strategic human resource management (SHRM) theories, it can be argued that LDP bundles or a set of complementary practices are likely to exert a synergistic effect on the organization's intangible strategic assets (Huselid, 1995; Delery, 1998; Guest, Conway, \& Dewe, 2004). This logic suggests that the bundling of complementary leadership development practices is likely to produce stronger effects on targeted skills or behaviors as opposed to practices that are individually implemented. For instance, combining one-on-one coaching with 360-degree 
feedback is likely to have a stronger effect on skill development than any one of these practices in itself (see Smither, London, Flautt, Vargas, \& Kucine, 2003). Similarly, providing mentoring to participants involved in challenging job assignments might enhance their skill development (Lankau \& Scandura, 2002).

In his seminal review of leadership development literature, Day (2000) distinguished between 'differentiation' developmental practices aimed primarily at directly building the individual unique self-image, intrapersonal knowledge, skills, and abilities (KSA's) of specific leaders through the use of assessment tools (e.g., assessment centers and multisource or 360 degree feedback), internal and external formal training, and support (e.g., mentoring and coaching); and 'integration' developmental practices, e.g., action learning, network events, stretch assignments, job rotations that contribute to organizational goals (e.g., increased revenues, corporate social responsibility) by developing extended social networks, coordination and commitments, while simultaneously building individuals leaders' interpersonal knowledge, skills, and abilities. Further, he argued that "an overall approach to leadership development as a type of organizational development strategy requires a purposeful transformation toward higher levels of both integration and transformation (p. 586)". Taking this view, we conceptualized and measured LDP in this study in the form of differentiation and integration bundles.

Together with evidence for the positive effect of traditional leadership training (e.g. Avolio, Reichard, Hannah, Walumbwa, \& Chan, 2009), studies indicate that other differentiation development practices can exert a positive influence on the development of inter- and intrapersonal competencies. For instance, there is evidence that individual coaching can increase self-regulation, coping with job demand, and job performance (Theeboom, Beersma, \& van Vianen, 2013), as well as social competencies (Grief, 2007); 360-degree feedback can improve leadership performance (Smither, London, \& Reilly, 2005); and mentoring has been shown to lead to leader efficacy and trust between mentor/mentee (Lester, Hannah, Harms, Vogelgesang, \& Avolio, 2011). Similar effects have also been noted for integration development practices. For instance, service learning programs have been reported to lead to self-development, a responsible and global mind-set, ethical literacy, cultural intelligence and interpersonal community building skills, which include stakeholder engagement, interpersonal skills, and relationship management (Pless, Maak \& Stahl, 2011). Stretch job assignments have been shown to lead to intrapersonal skills such as broader business knowledge, insightfulness, courage to take a stand, commitment to success, and act with integrity, in addition to interpersonal skills such as 'bringing out the best in people by pulling them around a common goal' (Dragoni et al., 2009). Job rotation can increase intrapersonal skills such as adaptability and flexibility and building a broader perspective on the business (Campion, Cheraskin \& Stevens, 1994), while action-learning experiences have been found to build personal meaning for individuals (McGregor \& Little, 1998) and potentially collective leadership (Raelin, 2006). Finally, network events/offsites where information is exchanged on new products can help in the creation of social capital (Galli \& Müller-Stewens, 2012).

Hypothesis 1: Differentiation and integration leadership development practices are positively related to organization-level human capital.

Hypothesis 2: Differentiation and integration leadership development practices are positively related to organization-level social capital. 
While most intangible assets or resources can either be acquired by the firm from the external strategic factor market or developed and accumulated internally (Maritan \& Peteraf, 2011), stocks of firm-specific human capital (i.e., employees' knowledge, skills, and abilities related to organizational products and processes) need to be built up over time in order to provide the firm with a competitive advantage (Dierickx \& Cool, 1989). This is because competitors cannot easily imitate the unique ways in which these assets are leveraged by the firm, as well as the interdependencies between these assets and the firm's existing resources and capabilities (Leiblein, 2011). Further, the tacit knowledge related to organizational processes and social systems cannot be easily developed by competitors over a compressed time period (Hatch \& Dyer, 2004). Firm-specific human capital can be accumulated through multiple routes, two of which have received particular interest in literature: training and experience on the job (Hitt, Bierman, Shimizu, \& Kochhar, 2001; Ployhart, et al., 2009). While training allows for the systematic acquisition of job- and firm-related knowledge and skills through instruction or codified language; experience within the organization is a chief means of developing tacit knowledge composed of skills and perspectives rooted in social experience (Nonaka, 1994). Indeed, recent meta-analytic evidence gathered from over 68 studies indicates a significant positive relationship between firm-level human capital and organizational performance (Crook et al., 2011). As we argued in the previous section, building leadership capability through LDP is likely to lead to a higher aggregate level of human capital within the organization. Thus, it can be hypothesized that:

\section{Hypothesis 3: Organization-level human capital will mediate the relationship between differentiation and integration leadership development practices and organizational performance.}

In addition to human capital, we view social capital as a potential mediator of the relationship between LDP and organizational performance. Unlike human capital, the empirical literature linking social capital and firm-performance is relatively sparse. However, various theorists have proposed ways in which the knowledge embedded in relationships between people can affect the organization's performance. For instance, employees who have strong interpersonal relational ties are likely to be more committed to the organization (Leana \& Van Buren, 1999); and display higher levels of trust thereby engaging in higher levels of information exchange (Tsai \& Ghoshal, 1998). Moreover, there is evidence that social capital can enhance knowledge flow and transfer within the organization and increase both organizational growth and innovation (Maurer, Bartsch, \& Ebers, 2011). Therefore we hypothesize:

Hypothesis 4: Organization-level social capital will mediate the relationship between differentiation and integration leadership development practices and organizational performance.

\section{METHODOLOGY}

\section{Sample and Procedure}

The data for this study were collected using an online survey administered to the full membership of the Indian chapter of Society of Human Resource Management (SHRM) which 
was estimated to be 1000 human resource managers affiliated with for- and non-profit organizations in India. As part of the survey, respondents were expected to report on various items dealing with their organization's leadership development practices. Therefore, the instructions to the survey clearly indicated that they should respond to the survey only if they had responsibility and or significant familiarity with the leadership development practices within their organization. Completed and valid results were received from 223 managers responding to as many organizations in our sample (response rate of $22.3 \%$ ). The organizations represented in our sample had a median workforce size of 1200 and median revenue of US \$16.16 million.

\section{Measures}

Leadership Development Practices. The LDP scale consisted of 13 items measured on a 5 point scale ranging from 'not at all used' to 'used to a very large extent' with the following stem: "Please estimate to what extent the following leadership development activities are used in your organization in the past fiscal year". The developmental practices and experiences included in this scale were derived from literature - specifically, McCauley (1994), Douglas and McCauley (1999), and Day (2000); and validated by three leadership development practitioners with graduate degrees in organizational psychology and an average of 15 years of full-time experience in designing, implementing, and assessing leadership development programs. A Principal Components Analysis of this scale with varimax rotation (Eigen Value $\geq 1$ ) revealed two factors accounting for $29 \%$ and $25 \%$ of the variance in the scale, that corresponded to 'differentiation LDP' (training, assessment centers, 360-degree feedback, formal mentoring, and coaching) and 'integration LDP' (job rotation, stretch assignments, network events, action learning, service learning, and strategic challenges). After establishing that the internal consistency of the items loading on these factors were high (Cronbach Alpha of $\alpha=.84$ for differentiation LDP, and $\alpha=$ .85 for integration LDP), we created item composites and used those in our analyses.

Human Capital and Social Capital. We measured human and social capital utilizing 9 items from the intellectual capital scale developed and validated by Youndt and Snell (2004). Because these authors had already established the 2-factor structure of this scale (i.e., human capital and social capital), we conducted a confirmatory factor analysis (CFA) to confirm this structure in our own dataset. Next, we established that the internal consistency of the items loading on these factors were high (Cronbach Alpha of $\alpha=.87$ for human capital, and $\alpha=.83$ for social capital) and created item composites to be used in our analyses.

Organizational Outcomes. We measured two different indicators of organizational performance in our study. The first was a measure of economic performance common in literature - sales growth or change in sales (e.g., Batt, 2002), which we measured as the difference in total sales between the fiscal year of the survey and the previous fiscal year (i.e., the time period for which the leadership development practices were reported). Our second outcome measure reflected the organization's innovation, and was operationalized as the 'total percentage of sales in the current fiscal year generated from new products or services'. This measure - also known as 'new product success' has been used in strategy literature as a measure of a firm's innovation performance (e.g., Dul \& Ceylan, 2014).

Controls. We controlled for organization size (number of full time equivalent employees), service intensity (percentage of sales generated through services), industry competitiveness (item: "Our industry has a lot of competitive pressures"), and differentiation 
strategy (item: "We follow an overall strategy that emphasizes providing distinctive / and superior levels of service") in our entire analysis.

\section{RESULTS}

All hypothesized relationships were tested using structural equations modeling (SEM) implemented in AMOS 21.0 (Arbuckle, 2012), with item composites of differentiation LDP, integration LDP, human capital, and social capital utilized as manifest indicators for their corresponding latent variables.

Consistent with hypothesis 1 , both differentiation $\operatorname{LDP}(\beta=.36 ; \mathrm{B}[\mathrm{SE}]=.30[.06] ; \mathrm{p}$ $=.001)$ and integration $\operatorname{LDP}(\beta=.25 ; \mathrm{B}[\mathrm{SE}]=.20[.06] ; \mathrm{p}=.001)$ were significant predictors of, and together accounted for $32 \%(\mathrm{R} 2=.32 ; \mathrm{p}=.001)$ of the variance in, human capital. Similarly differentiation LDP $(\beta=.25 ; \mathrm{B}[\mathrm{SE}]=.23[.07] ; \mathrm{p}=.001)$ and integration $\operatorname{LDP}(\beta=.31 ; \mathrm{B}[\mathrm{SE}]=$ .28 [.07]; $\mathrm{p}=.001)$ were significant predictors of social capital and accounted for $26 \%(\mathrm{R} 2=.26$; $\mathrm{p}=.001)$ of the variance in this outcome, thus supporting hypothesis 2 . Further, human capital was found to be a significant predictor of change in sales $(\beta=.17 ; \mathrm{B}[\mathrm{SE}]=\$ 1874.21$ [890.10] million; $\mathrm{p}=.03 ; \mathrm{sr} 2=.02)$, but not innovation $(\beta=.06 ; \mathrm{ns})$. We also found that social capital did not predict innovation $(\beta=.13$; ns) or change in sales $(\beta=-.07$; ns). However, after constraining the effect of human capital on innovation and social capital on sales change by setting these paths to zero, we found that human capital had a slightly stronger relationship with sales change $(\beta=.17 ; \mathrm{B}[\mathrm{SE}]=\$ 1479.53$ [676.59] million; $\mathrm{p}=.03 ; \mathrm{sr} 2=.02)$, while social capital significantly predicted innovation $(\beta=.17 ; \mathrm{B}[\mathrm{SE}]=4.29[1.77] ; \mathrm{p}=.02 ; \mathrm{sr} 2=.03)$. Further, this model $(\chi 2$ $[15]=27.97, \mathrm{p}=.02 ; \mathrm{RMSEA}=.06 ; \mathrm{CFI}=.97$; $\mathrm{NFI}=.95 ; \mathrm{ECVI}=.58 ; \mathrm{PNFI}=.27)$ demonstrated good fit with the data.

In testing hypotheses 3 and 4, we examined the fully mediated relationships between (a) differentiation LDP, human capital, and change in sales, (b) integration LDP, human capital, and change in sales, (c) differentiation LDP, social capital, and innovation, (b) integration LDP, social capital, and innovation utilizing the bootstrapping approach (Shrout \& Bolger, 2002) with the Bias Corrected (BC) percentile method (Mooney \& Duval, 1993). Specifically, we tested the significance of these four mediated (i.e., indirect) effects utilizing $95 \%$ confidence intervals drawing 1,000 random (with replacement) bootstrap samples of the observations. The results of bootstrapping revealed that the relationship between differentiation LDP and change in sales was fully mediated by human capital $(\beta=.07 ; p=.01 ; 95 \% \mathrm{CI}$ : .03 to .15$)$. While all the other mediated relationships were non-significant, it should be noted the integration LDP $\rightarrow$ social capital $\rightarrow$ innovation mediation relationship approached significance $(\beta=.04 ; p=.08)$. Thus, in sum, hypothesis 3 was partially supported while hypothesis 4 was not supported.

\section{DISCUSSION}

We hypothesized and discovered positive relationships between two types of LDP bundles - differentiation and integration - and two forms of organization-level intangible assets, i.e., human and social capital in a sample of 223 organizations in India. Further, we found that organization-level human capital fully mediated the relationship between the differentiation bundle (consisting of practices aimed at increasing individual leaders' self-awareness and competence) and organizational performance, as measured by sales growth. These findings suggest that organizational investments into the development of leadership capability are likely 
to yield benefits in the form of accumulation of these intangible assets and ultimately, financial performance.

Our results contribute to leadership development literature in four ways. First, in contrast with previous theoretical work in this domain (see Dinh, Lord, Gardner, Meuser, Liden, \& Hu, 2014) we conceptualized leadership development practices as an organization-level investment and examined its influence on firm-level outcomes. This can be seen both, as a contribution to extant leadership development theory, and as an extension of the large body of literature in SHRM linking HRM systems to firm-performance (e.g., Jiang, Lepak, Hu, \& Baer, 2012). Second, we provided an empirical validation of the proposition that investments in leadership development are related to human- and social-capital (Day, 2000) albeit at the organization-level of analysis. Our findings suggest that both types of LDP bundles - differentiation and integration, are positively related to both, human and social capital, i.e., the aggregate knowledge, skills, and abilities of the organization's workforce and the relationships between its various constituents. Third, we demonstrated an indirect or mediated relationship between specific types of leadership development (i.e., differentiation practices) and organizational performance, thereby establishing an empirical value of such investments. To our knowledge, this is the first scholarly examination of this link utilizing a comprehensive list of developmental practices, mediators, and performance outcomes in the literature. Fourth, this study respond to the call for rigorous studies of HRM related phenomena in emerging economies like India (e.g., Budhwar \& Varma, 2010), and demonstrates that within these dynamic contexts, leadership development can help build organizational capability and influence financial performance.

Contrary to our expectations, we did not find a positive relationship between social capital and organizational performance, particularly sales growth, in the current study. This might be because unlike human capital, social capital - which is inherent in the relationships between people - cannot be easily mobilized toward economic ends (e.g., it takes time to convert a cross-departmental partnership into actions that lead the firm to sell more products), and it is possible that the overall effects of this intangible assets on financial performance can only be noticed over long periods of time. However, controlling for the effects of human capital, we did find a significant positive relationship between social capital and innovation - a more proximal outcome variable, suggesting that organizations with larger stocks of social capital are likely to generate higher levels of creative outputs that are then translated into a higher proportion of new products and services. This is clearly an area requiring further research.

Our study has several limitations. First, while we asked our respondents to report on the LDP practices in the previous year and the performance outcomes in the current year, our study's design itself can be considered cross-sectional and our determined effects of human capital are therefore, likely to be underestimates of the long term effects of these variables. Second, our study was conducted within one national context (India), and needs to be replicated within other nations to be considered truly generalizable. Third, while we attempted to obtain multiple responses from the organizations in our sample to rule out common source variance, we were not successful in having different judges provide us with different pieces of information about the organization's leadership development practices and outcomes. We encourage other researchers to continue attempting various procedures to obtain such multiple responses.

TABLES, FIGURES, AND REFERENCES ARE AVAILABLE FROM THE AUTHORS 